\title{
Synthesis, structure and solvatochromic properties of some novel 5-arylazo-6-hydroxy-4- phenyl-3-cyano-2-pyridone dyes
}

\author{
Adel Alimmari ${ }^{1}$, Dušan Mijin ${ }^{1 *}$, Radovan Vukićević ${ }^{1}$, Bojan Božić ${ }^{1}$, Nataša Valentić ${ }^{1}$, Vesna Vitnik², Željko Vitnik ${ }^{3}$ \\ and Gordana Ušćumlić ${ }^{1}$
}

\begin{abstract}
Background: A series of some novel arylazo pyridone dyes was synthesized from the corresponding diazonium salt and 6-hydroxy-4-phenyl-3-cyano-2-pyridone using a classical reaction for the synthesis of the azo compounds.

Results: The structure of the dyes was confirmed by UV-vis, FT-IR, ${ }^{1} H$ NMR and ${ }^{13} \mathrm{C}$ NMR spectroscopic techniques and elemental analysis. The solvatochromic behavior of the dyes was evaluated with respect to their visible absorption properties in various solvents.

Conclusions: The azo-hydrazone tautomeric equilibration was found to depend on the substituents as well as on the solvent. The geometry data of the investigated dyes were obtained using DFT quantum-chemical calculations. The obtained calculational results are in very good agreement with the experimental data.
\end{abstract}

Keywords: Arylazo pyridone dyes, Tautomerism, Solvent effect, Substituent effect, DFT caculation

\section{Background}

Azo dyes are the most widely used compounds in various fields, such as the dyeing of textiles, in biologicalmedical studies and advanced applications in organic synthesis [1-4]. The success of azo colorants is due to the simplicity of their synthesis by diazotization and azo coupling, the almost innumerable possibilities presented by variation of the diazo compound and coupling component, the generally high molar extinction coefficient and the medium to high light and wet fastness properties [5]. In recent years, azo dyes have gained wide interest and found many uses in materials for optical applications and in analysis. Due to their properties, including optical storage capacity, optical switching, holography and non-linear optical properties, polymers with azo units represent promising candidates for photoactive materials [6]. Pyridone derivatives are heterocyclic intermediates relatively recently employed for the preparation of arylazo dyes and several investigations on

\footnotetext{
* Correspondence: kavur@tmf.bg.ac.rs

'Department of Organic Chemistry, Faculty of Technology and Metallurgy, University of Belgrade, Karnegijeva 4, P.O. Box 3503, 11120 Belgrade, Serbia Full list of author information is available at the end of the article
}

substituted arylazo pyridones were performed and reviewed [7-12]. The physico-chemical properties of these dyes are closely related to their tautomerism. Determination of azo-hydrazone tautomers in both the solid state and solution phase is quite interesting from both the theoretical and practical standpoints, since the tautomers have different technical properties and dyeing performances. In previous publications, the absorption spectra of ten 5-arylazo-6-hydroxy-4-methyl-3-cyano-2pyridones in different solvents were studied and the results showed that these dyes exist in the hydrazone tautomeric form in the solid state and in the solvent DMSO- $\mathrm{d}_{6}$ while equilibriums exist between the hydrazone and the azo form in different solvents [13].

In this work, the synthesis of twelve new 5-arylazo-6hydroxy-4-phenyl-3-cyano-2-pyridones (Scheme 1), their UV-vis absorption spectra (200-600 nm) in thirteen solvents of different polarity and the relationship between color and the constitution of these dyes are reported. The effects of the solvent and the substituent on the azohydrazone tautomeric equilibrium, and the geometry data of the investigated dyes, obtained using DFT quantumchemical calculations, were studied and evaluated. 


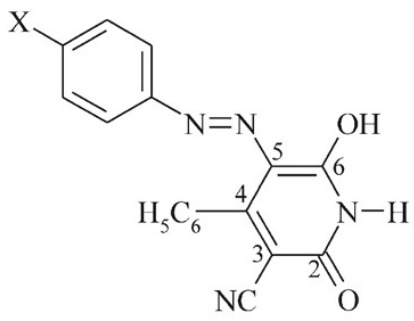

A

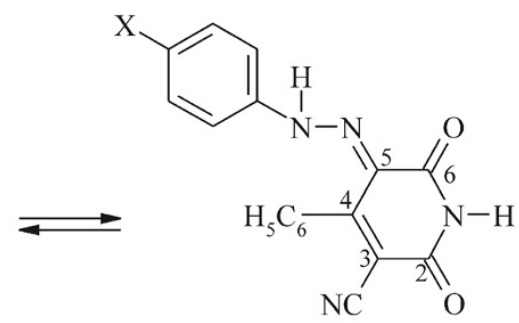

B

Scheme 1 The equilibrium between the azo form $(A)$ and the hydrazone form (B) of 5-arylazo-6-hydroxy-4-phenyl-3-cyano-2pyridones. $\left(\mathrm{X}=\mathrm{H}(\mathbf{1}), \mathrm{OH}(\mathbf{2}), \mathrm{OCH}_{3}(\mathbf{3}), \mathrm{CH}_{3}(\mathbf{4}), \mathrm{Cl}(\mathbf{5}), \mathrm{Br}(\mathbf{6}), \mathrm{I}\right.$ (7), $\mathrm{F}(\mathbf{8}), \mathrm{CN}(\mathbf{9}), \mathrm{COOH}(\mathbf{1 0}), \mathrm{COCH}_{3}(\mathbf{1 1}), \mathrm{NO}_{2}(\mathbf{1 2})$ ).

\section{Experimental \\ General}

All starting materials were obtained from Aldrich and Fluka, and were used without further purification.

The IR spectra were determined using a Bomem MBSeries Fourier Transform-infrared (FT-IR) spectrophotometer in the form of $\mathrm{KBr}$ pellets. The ${ }^{13} \mathrm{C}$ and ${ }^{1} \mathrm{H}$ NMR spectral measurements were performed on a Varian Gemini 2000 (200 MHz). The spectra were recorded at room temperature in deuterated dimethyl sulfoxide $\left(\right.$ DMSO- $\left.\mathrm{d}_{6}\right)$. The chemical shifts are expressed in ppm values referenced to TMS. The ultraviolet-visible (UVvis) absorption spectra were recorded on a Schimadzu 1700 spectrophotometer in the region $200-600 \mathrm{~nm}$. The spectra were run in spectroquality solvents (Fluka) using concentration of $1 \times 10^{-5} \mathrm{M}$. All melting points were uncorrected and are in degree Celsius. Elemental analysis was performed using a VARIO EL III elemental analyzer. Characterization data are given in Additional files 1, 2, 3, $4,5,6,7$.

\section{Preparation of 5-arylazo-6-hydroxy-4-phenyl-3-cyano-2- pyridone dyes (1-12)}

All the investigated arylazo pyridone dyes were synthesized from the corresponding diazonium salts and 4phenyl-6-hydroxy-3-cyano-2-pyridone using a classical reaction for the synthesis of azo compounds [5]. 4Phenyl-6-hydroxy-3-cyano-2-pyridone was prepared from ethyl benzoylacetate and cyanoacetamide using a modified literature procedure [14].

The yields of the dyes were in the range 50-75\%.

\section{Results and discussion}

\section{Spectral characteristics and tautomerism}

The arylazo pyridone dyes prepared in this work may exist in two main tautomeric forms (Scheme 1). Generally, tautomers not only have different colors, but also have different tinctorial strength and different properties, e.g., light fastness [7]. Due to the commercial importance of arylazo pyridone dyes, the azo-hydrazone tautomerism has been intensively studied [15-17]. It was concluded that the equilibrium between the two tautomers is influenced by the structure of the compound and the solvent used [15-17].

The infrared spectra of all the synthesized dyes showed two intense carbonyl bands at about 1630 and $1684 \mathrm{~cm}^{-1}$, which were assigned to the diketohydrazone form. The FT-IR spectra also showed a band at 3110-3217 $\mathrm{cm}^{-1}$, assigned to the imino group $(\mathrm{N}-\mathrm{H})$ of the heterocyclic (pyridone) ring and a band at $3382-3414 \mathrm{~cm}^{-1}$ that was assigned to the $\mathrm{N}-\mathrm{H}$ of hydrazo tautomeric form.

The ${ }^{1} \mathrm{H}$ NMR spectra of the dyes exhibited a broad signal near 14.27-14.93 ppm. This signal corresponds to the imine $\mathrm{N}-\mathrm{H}$ proton resonance of the hydrazone form (Scheme 1, Structure B). In our previous publication [13], the ${ }^{1} \mathrm{H}$ NMR spectra of ten 5-arylazo-6-hydroxy-4methyl-3-cyano-2-pyridones were studied and the results showed that these dyes existed in the hydrazone tautomeric form in the solid state and in the solvent DMSO$\mathrm{d}_{6}$, with $\mathrm{N}-\mathrm{H}$ peaks in the range $14.35-14.87 \mathrm{ppm}$.

N. Ertan et al. [10] reported the ${ }^{1} \mathrm{H}$ NMR spectra of some azo pyridone dyes in $\mathrm{CF}_{3} \mathrm{COOD} / \mathrm{CDCl}_{3}$ and showed that these dyes existed in the hydrazone form with the $\mathrm{N}-\mathrm{H}$ peak in the range $15.10-15.60 \mathrm{ppm}$. Q. Peng et al. $[5,15]$ also reported the ${ }^{1} \mathrm{H}$ NMR spectra of azo pyridone dyes in $\mathrm{CDCl}_{3}$ and concluded that the azo pyridone dyes exist in the hydrazone form and with the $\mathrm{N}-\mathrm{H}$ peaks appearing within the range 14.30-16.09 ppm.

Lucka and Machacek [18] and Cee et al. [19] concluded from ${ }^{13} \mathrm{C}$ NMR studies of some $\mathrm{N}$-alkyl derivatives of azopyridones that pyridone azo dyes in $\mathrm{CDCl}_{3}$ and DMSO- $\mathrm{d}_{6}$ exist in the hydrazone form. Our results are in agreement with these results.

\section{Solvent effects}

Since the tautomeric equilibria strongly depend on the nature of the media, the behavior of selected arylazo pyridone dyes in thirteen protic and aprotic solvents was studied. For this purpose, the absorption spectra of the pyridone dyes (1-12) at a concentration $1 \times 10^{-5} \mathrm{~mol}$ $\mathrm{dm}^{-3}$ were recorded over the $\lambda$ range between 200 and $600 \mathrm{~nm}$ in the selected solvent set. The characteristic 


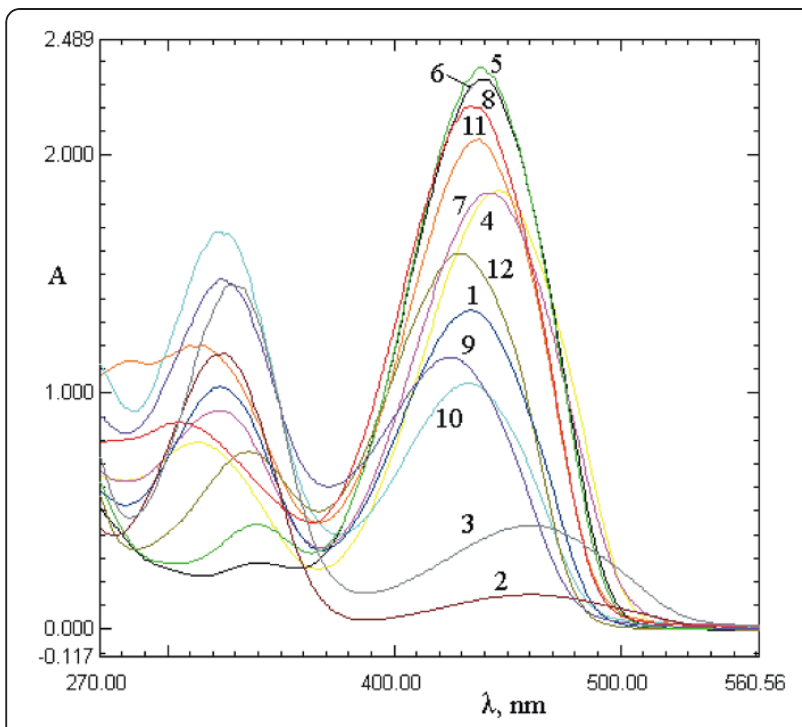

Figure 1 Absorption spectra of dyes 1-12 in methanol.

absorption spectra of the investigated azo dyes in methanol and dimethyl sulfoxide are shown in Figures 1 and 2 .

The UV-vis absorption spectra of all the dyes showed a weak band at about 260-370 nm, assigned to the azo tautomeric form and a strong band at 375-550 nm, which was assigned to hydrazone tautomeric form. The absorption maxima, which correspond to a transition in which electron density is transferred from the hydrazone -NH group to the pyridone carbonyl group (lower energy band), are presented in Tables 1 and 2. It was observed that, although slightly positive solvatochromism is evident, the absorption spectra of dyes 1-12 did not change significantly in all the employed solvents and

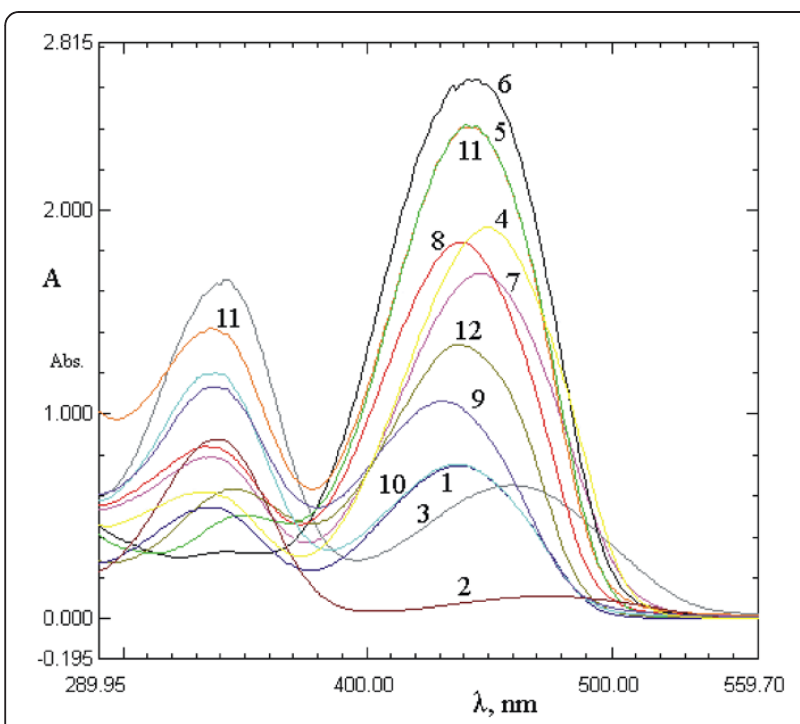

Figure 2 Absorption spectra of dyes 1-12 in dimethyl sulfoxide. the absorption maxima did not correlate with the polarity of the solvent.

Additional evidence for the solvent effect on the structure-property relationship of arylazo pyridone dyes was obtained from the correlation of the absorption frequencies $\left(v=1 / \lambda\right.$ in $\left.\mathrm{cm}^{-1}\right)$ for the hydrazone tautomeric form (Tables 1 and 2) with the Kamlet-Taft Solvatochromic Equation (1) [20] of the following form:

$$
v=v_{0}+s \pi *+b \beta+a \alpha
$$

where $\pi^{*}$ is an index of the solvent dipolarity / polarizability, $\beta$ is a measure of the solvent hydrogen-bonding acceptor (HBA) basicity, $\alpha$ is a measure of the solvent hydrogen-bonding donor (HBD) acidity and $v_{0}$ is the regression value of the solute property in cyclohexane as the reference solvent. The regression coefficients $s, b$ and $a$ in Eq. 1 are a measure the relative susceptibilities of the absorption frequencies to the indicated solvent parameters. The linear solvation energy relationship (LSER) concept developed by Kamlet and Taft is one of the most ambitions and successful quantitative treatments of solvation effects. This treatment assumes attractive interactions between a solute and its environment and enables an estimation of the ability of the investigated compounds to form hydrogen bonds. The solvent parameters [21] are given in Table 3. The correlations of the absorption frequencies $v_{\max }$ for hydrazone tautomer were realized by means of multiple linear regression analysis. It was found that $v_{\max }$ in the selected solvent sets showed satisfactory correlation with the $\pi^{*}, \beta$ and $\alpha$ parameters. The results of the multiple regressions are presented in Tables 4 and 5, and the coefficients $v_{0}, s, b$ and $a$ (Table 4) fitted at the 95 $\%$ confidence level. The negative sign of the $a$ coefficient (Table 4) for all dyes (excluding the $\mathrm{H}, \mathrm{CN}$, $\mathrm{COOH}$ and $\mathrm{NO}_{2}$ substituents) and the $s$ and $b$ coefficients for strong electron-donating substituents and strong electron-accepting substituents indicate a bathochromic shifts with increasing solvent dipolarity / polarizability and solvent hydrogen bond acidity and basicity. This suggests stabilization of the electron excited state relative to the ground state. The positive sign of the $a$ coefficient for strong electron-accepting substituents and the $s$ and $b$ coefficients for moderate electron-donating and electronaccepting substituents indicate hypsochromic shifts with increasing solvent dipolarity / polarizability and both types of hydrogen bonding effects. These results showed that the solvent effect on the UV-vis absorption spectra of the investigated azo pyridone dyes is very complex and strongly dependent on the nature of the substituent on the arylazo component. They also indicated that the electronic behavior of the nitrogen atoms of hydrazone group are somewhat different between derivatives with electrondonating and electron-accepting substituents (Figure 3, 
Table 1 Absorption maxima of the hydrazone tautomer (B) of arylazo pyridone dyes (1-12) in protic solvents

\begin{tabular}{|c|c|c|c|c|c|c|}
\hline \multirow{2}{*}{$\begin{array}{l}\text { Dye } \\
\text { No. }\end{array}$} & \multicolumn{6}{|c|}{$\lambda_{\max }(\mathrm{nm})$} \\
\hline & Methanol & Ethanol & Propan-1-ol & Propan-2-ol & Butan-1-ol & 2-Methylpropan-2-ol \\
\hline 1 & 433 & 434 & 434 & 433 & 433 & 431 \\
\hline 2 & 460 & 470 & 476 & 472 & 470 & 474 \\
\hline 3 & 460 & 458 & 458 & 455 & 448 & 454 \\
\hline 4 & 445 & 446 & 447 & 445 & 446 & 445 \\
\hline 5 & 437 & 435 & 438 & 439 & 439 & 439 \\
\hline 6 & 437 & 438 & 438 & 438 & 442 & 440 \\
\hline 7 & 440 & 442 & 443 & 442 & 442 & 442 \\
\hline 8 & 433 & 436 & 436 & 434 & 436 & 436 \\
\hline 9 & 424 & 426 & 425 & 425 & 425 & 424 \\
\hline 10 & 432 & 432 & 433 & 433 & 433 & 433 \\
\hline 11 & 437 & 436 & 436 & 435 & 435 & 435 \\
\hline 12 & 429 & 428 & 429 & 428 & 428 & 427 \\
\hline
\end{tabular}

Structures $\mathbf{C}$ and $\mathbf{D})$. This phenomenon is caused by the difference in the conjugational or migrating ability of the electron lone pairs on the nitrogen atoms of the pyridone azo dyes. The strong electron-donating substituents in the phenyl group produce extensive delocalization in the arylazo group (Figure 3, Structure D), while the influence of the strong electron-accepting substituents are opposite, due to the positive charge on the nitrogen atom in the hydrazone tautomer (Figure 3, Structure C).

The percentage contributions of the solvatochromic parameters (Table 5) for the azo dyes with strong and moderate electron-accepting substituents on the arylazo group, showed that the most of the solvatochromism is due to the solvent dipolarity / polarizability rather than to the solvent acidity and basicity. These results could be explained by the effect of the positive charge on the nitrogen atom in the hydrazone tautomer (Figure 3, Structure C) and stabilization of this form mostly due to the solvent dipolarity / polarizability (non-specific solutesolvent interactions) than by hydrogen bond donating and hydrogen bond accepting properties (specific solutesolvent interactions).

\section{Substituent effects}

As seen in Tables 1 and 2, the absorption spectra of the $p$-nitro derivative (dye 12) were shifted hypsochromically in all used solvents (excluding DMSO and DMF) when compared with dye 1 . Moreover, the absorption spectra of the $p$-hydroxy and $p$-methoxy derivatives (dyes 2 and 3 ) were shifted bathochromically in all used solvents when compared with dye $\mathbf{1}$. It is well known that the $\lambda_{\max }$ values of the hydrazone tautomeric form of an azo dyes

Table 2 Absorption maxima of hydrazone tautomer (B) of arylazo pyridone dyes (1-12) in aprotic solvents

\begin{tabular}{|c|c|c|c|c|c|c|c|}
\hline \multirow{2}{*}{$\begin{array}{l}\text { Dye } \\
\text { No. }\end{array}$} & \multicolumn{7}{|c|}{$\lambda_{\max }(\mathrm{nm})$} \\
\hline & Tetrahydrofuran & Dioxane & Methyl acetate & Ethyl acetate & Dimethylformamide & Dimethylacetamide & Dimethyl sulfoxide \\
\hline 1 & 431 & 430 & 430 & 429 & 415 & 428 & 437 \\
\hline 2 & 466 & 461 & 460 & 460 & 470 & 470 & 473 \\
\hline 3 & 455 & 455 & 454 & 454 & 449 & 456 & 459 \\
\hline 4 & 442 & 442 & 441 & 440 & 423 & 441 & 449 \\
\hline 5 & 434 & 437 & 434 & 433 & 417 & 427 & 440 \\
\hline 6 & 436 & 437 & 434 & 433 & 421 & 425 & 441 \\
\hline 7 & 439 & 441 & 437 & 437 & 425 & 432 & 447 \\
\hline 8 & 432 & 432 & 431 & 429 & 410 & 422 & 437 \\
\hline 9 & 426 & 426 & 423 & 423 & 433 & 434 & 430 \\
\hline 10 & 431 & 432 & 429 & 429 & 431 & 433 & 437 \\
\hline 11 & 434 & 436 & 433 & 432 & 436 & 439 & 442 \\
\hline 12 & 429 & 430 & 427 & 427 & 451 & 452 & 437 \\
\hline
\end{tabular}


Table 3 Solvent parameters [21]

\begin{tabular}{lclll}
\hline No. & Solvent & $\boldsymbol{\pi}^{*}$ & $\boldsymbol{\beta}$ & $\boldsymbol{a}$ \\
\hline 1 & Methanol & 0.60 & 0.62 & 0.93 \\
2 & Ethanol & 0.54 & 0.77 & 0.83 \\
3 & Propan-1-ol & 0.52 & 0.83 & 0.8 \\
4 & Propan-2-ol & 0.48 & 0.95 & 0.76 \\
5 & Butan-1-ol & 0.47 & 0.88 & 0.79 \\
6 & 2-Methylpropan-2-ol & 0.41 & 0.11 & 0.68 \\
7 & Tetrahydrofuran & 0.58 & 0.55 & 0 \\
8 & Dioxane & 0.55 & 0.37 & 0 \\
9 & Methyl acetate & 0.60 & 0.42 & 0 \\
10 & Ethyl acetate & 0.55 & 0.45 & 0 \\
11 & N,N-Dimethylformamide & 0.88 & 0.69 & 0 \\
12 & N,N-Dimethylacetamide & 0.88 & 0.76 & 0 \\
13 & Dimethyl sulfoxide & 1.00 & 0.76 & 0 \\
\hline
\end{tabular}

Table 5 Percentage contribution of the solvatochromic parameters

\begin{tabular}{llll}
\hline Substituent & $\boldsymbol{P}_{\boldsymbol{\pi}^{*}}(\%)$ & $\boldsymbol{P}_{\boldsymbol{\beta}}(\%)$ & $\boldsymbol{P}_{\boldsymbol{\alpha}}(\%)$ \\
\hline $\mathrm{H}$ & 58 & 25 & 17 \\
$\mathrm{OH}$ & 33 & 54 & 13 \\
$\mathrm{OCH}_{3}$ & 55 & 19 & 26 \\
$\mathrm{CH}_{3}$ & 50 & 22 & 28 \\
$\mathrm{Cl}$ & 74 & 17 & 9 \\
$\mathrm{Br}$ & 76 & 14 & 40 \\
$\mathrm{I}$ & 73 & 18 & 9 \\
$\mathrm{~F}$ & 71 & 19 & 10 \\
$\mathrm{CN}$ & 66 & 28 & 6 \\
$\mathrm{COOH}$ & 65 & 30 & 5 \\
$\mathrm{COCH}_{3}$ & 70 & 18 & 12 \\
$\mathrm{NO}_{2}$ & 70 & 23 & 7 \\
\hline
\end{tabular}

Table 4 Regression fits to the solvatochromic parameters (Eq.1)

\begin{tabular}{|c|c|c|c|c|c|c|c|c|c|}
\hline No. & Substituent & $v_{0}\left(10^{3} \mathrm{~cm}^{-1}\right)$ & $s\left(10^{3} \mathrm{~cm}^{-1}\right)$ & $b\left(10^{3} \mathrm{~cm}^{-1}\right)$ & $a\left(10^{3} \mathrm{~cm}^{-1}\right)$ & $r^{a}$ & $s^{b}$ & $F^{c}$ & $\begin{array}{l}\text { Solvents used in } \\
\text { the calculation }\end{array}$ \\
\hline \multirow[t]{2}{*}{1} & $\mathrm{H}$ & 21.92 & 1.81 & 0.80 & 0.52 & 0.9789 & 0.078 & 46 & $1-11$ \\
\hline & & $( \pm 0.180)$ & $( \pm 0.240)$ & $( \pm 0.170)$ & $( \pm 0.100)$ & & & & \\
\hline \multirow[t]{2}{*}{2} & $\mathrm{OH}$ & 21.34 & -0.53 & -0.86 & -0.20 & 0.9417 & 0.099 & 21 & $2-13$ \\
\hline & & $( \pm 0.155)$ & $( \pm 0.269)$ & $( \pm 0.280)$ & $( \pm 0.191)$ & & & & \\
\hline \multirow[t]{2}{*}{3} & $\mathrm{OCH}_{3}$ & 23.02 & -0.66 & 0.22 & -0.31 & 0.9614 & 0.037 & 24 & $1-10,13$ \\
\hline & & $( \pm 0.159)$ & $( \pm 0.089)$ & $( \pm 0.078)$ & $( \pm 0.104)$ & & & & \\
\hline \multirow[t]{2}{*}{4} & $\mathrm{CH}_{3}$ & 23.02 & -0.44 & -0.19 & -0.24 & 0.8128 & 0.099 & 5 & $1-10,12,13$ \\
\hline & & $( \pm 0.159)$ & $( \pm 0.222)$ & $( \pm 0.197)$ & $( \pm 0.118)$ & & & & \\
\hline \multirow[t]{2}{*}{5} & $\mathrm{Cl}$ & 21.28 & 2.57 & 0.61 & -0.31 & 0.9802 & 0.081 & 57 & $1-11$ \\
\hline & & $( \pm 0.183)$ & $( \pm 0.246)$ & $( \pm 0.176)$ & $( \pm 0.098)$ & & & & \\
\hline \multirow[t]{2}{*}{6} & $\mathrm{Br}$ & 21.61 & 2.11 & 0.38 & -0.27 & 0.9703 & 0.085 & 38 & $1-11$ \\
\hline & & $( \pm 0.194)$ & $( \pm 0.260)$ & $( \pm 0.186)$ & $( \pm 0.104)$ & & & & \\
\hline \multirow[t]{2}{*}{7} & 1 & 21.39 & 2.01 & 0.50 & -0.25 & 0.9812 & 0.067 & 52 & $1-9,11$ \\
\hline & & $( \pm 0.164)$ & $( \pm 0.210)$ & $( \pm 0.147)$ & $( \pm 0.083)$ & & & & \\
\hline \multirow[t]{2}{*}{8} & F & 21.14 & 3.02 & 0.79 & -0.43 & 0.9738 & 0.113 & 43 & $1-11$ \\
\hline & & $( \pm 0.256)$ & $( \pm 0.344)$ & $( \pm 0.246)$ & $( \pm 0.138)$ & & & & \\
\hline \multirow[t]{2}{*}{9} & $\mathrm{CN}$ & 24.50 & -1.21 & -0.51 & 0.10 & 0.9862 & 0.042 & 71 & $1-7,10-12$ \\
\hline & & $( \pm 0.102)$ & $( \pm 0.114)$ & $( \pm 0.097)$ & $( \pm 0.051)$ & & & & \\
\hline \multirow[t]{2}{*}{10} & $\mathrm{COOH}$ & 24.58 & -1.25 & -0.57 & 0.09 & 0.9823 & 0.046 & 64 & $1-7,9-12$ \\
\hline & & $( \pm 0.097)$ & $( \pm 0.121)$ & $( \pm 0.098)$ & $( \pm 0.055)$ & & & & \\
\hline \multirow[t]{2}{*}{11} & $\mathrm{COCH}_{3}$ & 23.73 & -0.92 & -0.23 & -0.16 & 0.9878 & 0.027 & 94 & $1-12$ \\
\hline & & $( \pm 0.050)$ & $( \pm 0.062)$ & $( \pm 0.057)$ & $( \pm 0.033)$ & & & & \\
\hline \multirow[t]{2}{*}{12} & $\mathrm{NO}_{2}$ & 27.02 & -5.14 & -1.71 & 0.47 & 0.9735 & 0.176 & 42 & $1-7,9,10,12,13$ \\
\hline & & $( \pm 0.398)$ & $( \pm 0.533)$ & $( \pm 0.382)$ & $( \pm 0.214)$ & & & & \\
\hline
\end{tabular}

${ }^{\text {a }}$ Correlation coefficient.

b Standard error of the estimate.

c Fisher's test.

d Solvent number as given in Table 3. 


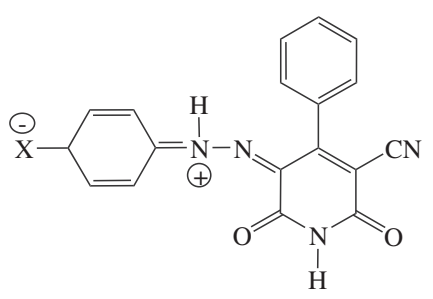

C

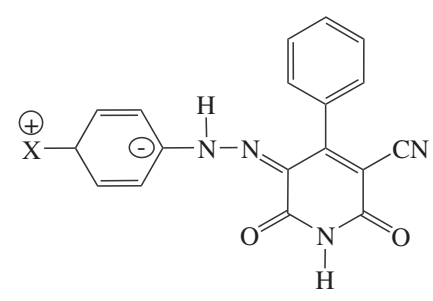

D

Figure 3 Resonance effect of electron-accepting (structure C) and electron-donating (structure D) substituents of the arylazo component on the hydrazone tautomer (B).

will show a general shift to shorter wavelengths when substituents of increasing electron withdrawing strength are introduced into the ring of the diazo component. In contrast, electron donor substituents produce strong bathochromic shifts [2]. The results presented in Tables 1 and 2 are in agreement with these conclusions. Thus, the observed relationship between the substituent constants and the $\lambda_{\max }$ values strongly suggests that the lower energy absorption maxima of the investigated azo dyes originate from hydrazones (Scheme 1, Structure B).

In order to explain these results, the absorption frequencies were correlated by the Hammett Equation (2) using $\sigma_{\mathrm{p}}$ or $\sigma_{\mathrm{p}+}$ substituent constants [22]:

$$
v=v_{0}+\rho \sigma_{\mathrm{p}}
$$

where $\rho$ is a proportionality constant reflecting the sensitivity of the absorption frequencies to the substituent effects. The substituent $\sigma_{\mathrm{p}}$ or $\sigma_{\mathrm{p}+}$ constants measure the electronic effect of the substituents. The plot $v_{\max } \nu s$. the $\sigma_{\mathrm{p}}$ substituent constants gave a correlation which showed deviations from the Hammet Equation in all dipolar aprotic solvents. However, a linear Hammett correlation was obtained in protic solvents. A better correlation of $v_{\max }$ was obtained with the $\sigma_{\mathrm{p}+}$ substituent constants [23] than

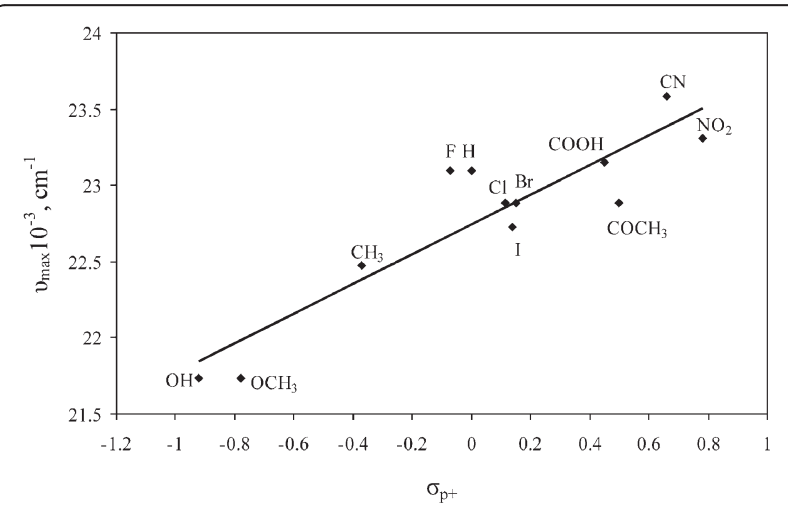

Figure 4 Relationship between $v_{\max }$ and $\sigma_{\mathrm{p}+}$ for arylazo pyridone dyes 1-12 in methanol. with the $\sigma_{\mathrm{p}}$ constants in all solvents, which indicates extensive delocalization in the arylazo group. The existence of the linear correlation with positive slope presented in Figure 4 and Equation 3 was interpreted as evidence of the diketohydrazone structure.

$$
\begin{aligned}
& v_{\max }=0.974 \sigma_{\mathrm{p}+}+22.744 \\
& (r=0.9114, s=0.25, F=49, n=12)
\end{aligned}
$$

\section{Quantum chemical calculations}

DFT calculations were performed for different azohydrazone tautomers of dye $\mathbf{1}$. The structures were preliminary optimized by the semi-empirical PM3 method and the most stable geometries in vacuum were reoptimized at the B3LYP/6-31G(d) level of theory [24,25]. The Gaussian 03 program package was used [26]. The DFT calculations suggested that the diketohydrazone form (B) (Figure 5) is the most stabile tautomer of dye $\mathbf{1}$. The relative energies and the statistical Boltzmann distribution weighted values of the most stable azo-hydrazone tautomers of dye $\mathbf{1}$ are given in Table 6.

\section{Conclusions}

In this work, twelve new 5-arylazo-6-hydroxy-4-phenyl-3cyano-2-pyridone dyes were synthesized. Characterization and the absorption ability of the dyes were studied. The results showed that the solvent effect on UV-vis absorption spectra of the investigated arylazo pyridone dyes is very complex and strongly depends on the nature of the substituent on the arylazo component. The introduction of electron-donating substituents into the arylazo ring results in strong bathochromic shifts in all solvents. These solvatochromic properties are evident for the hydrazone tautomeric form. The introduction of electron-accepting substituents into the arylazo moiety produces slight bathochromic or hypsochromic effects. The satisfactory correlation of the ultraviolet absorption frequencies of the hydrazone tautomeric form of the azo dyes with Eq. (1) indicates that the correct model was selected. It was demonstrated that a solvatochromic equation with three 


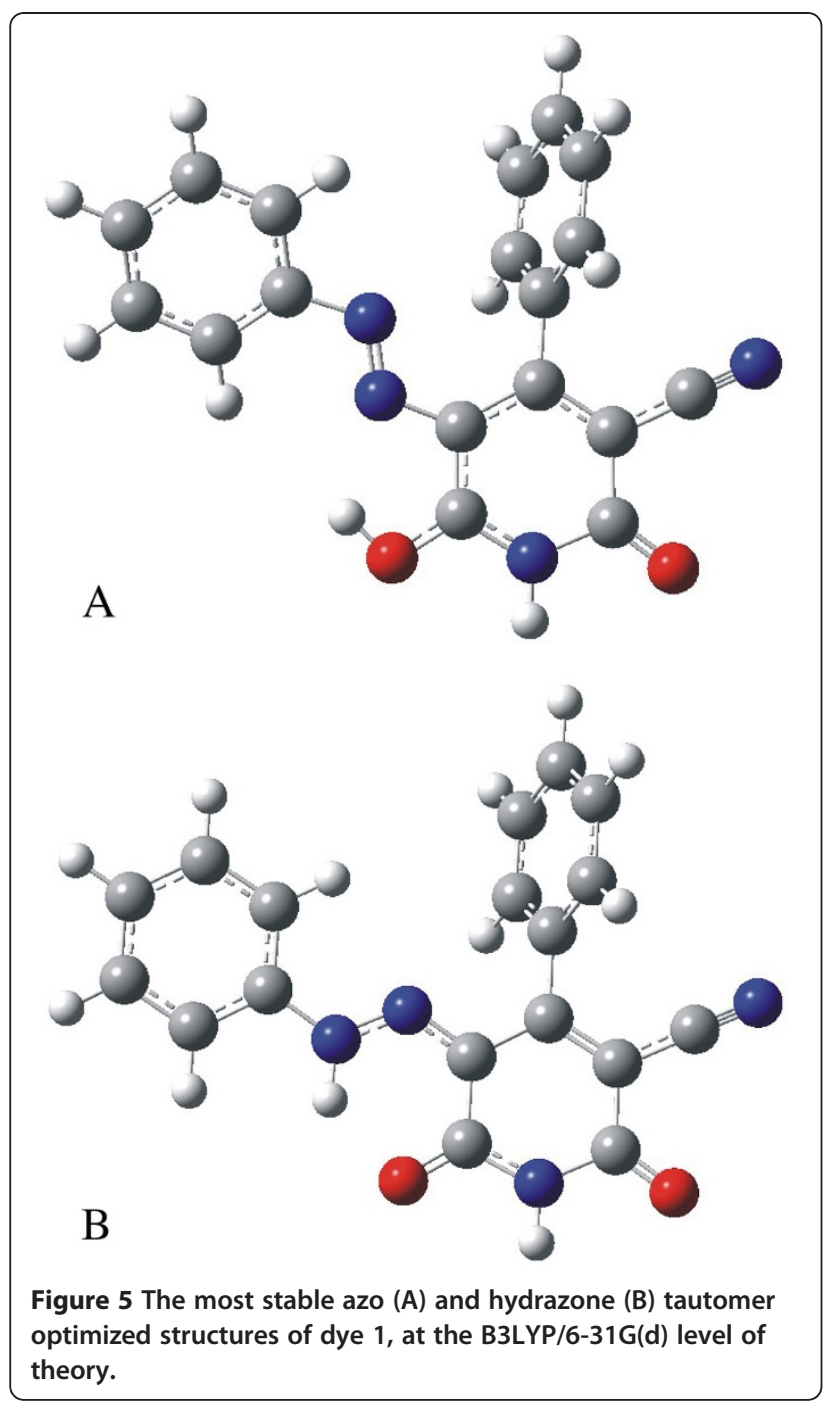

solvatochromic parameters $\pi^{*}, \beta$ and $\alpha$ can be used to evaluate the effects of both types of hydrogen bonding and of the solvent dipolarity / polarizability effect. All the synthesized dyes exist in the hydrazone tautomeric form in the solid state and dyes were predominantly as hydrazones in all the employed solvents. The calculational results of the geometry data of the investigated dyes, obtained using DFT quantum-chemical calculations, were in very good agreement with the experimental data.

Table 6 The relative energies ${ }^{a}$ and the statistical Boltzmann distribution weighted values of the most stable azo-hydrazone tautomers of dye 1

\begin{tabular}{lcc}
\hline $\begin{array}{l}\text { Tautomer } \\
\text { of dye } \mathbf{1}\end{array}$ & $\begin{array}{c}\text { Relative energies } \\
{\left[\mathrm{kcal} \mathrm{mol}^{\mathbf{1}} \text { ] }\right.}\end{array}$ & $\begin{array}{c}\text { Statistical Boltzmann distribution } \\
\text { weighted values [\%] }\end{array}$ \\
\hline A & 21.729 & 0.00 \\
B & 0.000 & 100.00 \\
\hline
\end{tabular}

${ }^{\mathrm{a}}$ The energies were calculated relative to the energy of the most stable tautomer (B) of dye $\mathbf{1}$, which represents an energy minimum (Data were obtained at the B3LYP/6-31G* level).

\section{Additional files}

Additional file 1: Experimental details and data of the investigated compounds. Additional file 1 includes the experimental procedures and the results of the physico-chemical characterization of the investigated compounds $[5,14]$.

Additional file 2: ${ }^{1} \mathrm{H}$ NMR (200 MHz, DMSO- $\left.d_{6}\right)$ spectra of 5-(4-bromophenylazo)-6-hydroxy-4-phenyl-3-cyano-2-pyridoine (6).

Additional file 3: ${ }^{13} \mathrm{C}$ NMR (50 MHz, DMSO- $d_{6}$ ) spectra of 5-(4-bromophenylazo)-6-hydroxy-4-phenyl-3-cyano-2-pyridoine (6). Additional file 4: IR spectra of 5-(4-bromophenylazo)-6-hydroxy-4phenyl-3-cyano-2-pyridoine (6).

Additional file 5: ${ }^{1} \mathrm{H}$ NMR (200 MHz, DMSO- $d_{6}$ ) spectra of 5-(4nitrophenylazo)-6-hydroxy-4-phenyl-3-cyano-2-pyridoine (12).

Additional file 6: ${ }^{13} \mathrm{C}$ NMR (50 MHz, DMSO- $d_{6}$ ) spectra of 5-(4nitrophenylazo)-6-hydroxy-4-phenyl-3-cyano-2-pyridoine (12).

Additional file 7: IR spectra of 5-(4-nitrophenylazo)-6-hydroxy-4phenyl-3-cyano-2-pyridoine (12).

\section{Competing interests}

The authors declare that they have no competing interests.

\section{Acknowledgements}

The authors acknowledge the financial support of the Ministry of Education and Science of the Republic of Serbia (Projects 172013 and 172035).

\section{Author details}

${ }^{1}$ Department of Organic Chemistry, Faculty of Technology and Metallurgy, University of Belgrade, Karnegijeva 4, P.O. Box 3503, 11120 Belgrade, Serbia. 2Department of Chemistry, ICTM, University of Belgrade, Studentski trg 12-16, 11000 Belgrade, Serbia. ${ }^{3}$ Faculty of Chemistry, University of Belgrade,

Studentski trg 12-16, 11000 Belgrade, Serbia.

\section{Authors' contributions}

$\mathrm{AA}, \mathrm{BB}$ and RV performed the synthesis and characterization of the compounds. NV, Ž V and W realized the calculations of the molecular descriptors and performed the statistical analysis. DM and GU conceived the study and participated in its design and coordination. All authors read and approved of the final manuscript.

Received: 20 April 2012 Accepted: 28 June 2012

Published: 23 July 2012

\section{References}

1. Zollinger H: Color chemistry: synthesis, properties, and application of organic dyes and pigments. Weinheim: Wiley-VCH; 2003.

2. Bhatti H, Seshadri S: Synthesis and fastness properties of styryl and azo disperse dyes derived from 6-nitro substituted 3-aryl-2-methyl-4(3H)quinazolinone. Color Technol 2004, 120:151-155.

3. Hallas G: Effects of terminal groups in 4-aminoazobenzene and disperse dyes related thereto. J Soc Dyers Colour 1979, 95:285-294.

4. Towns A: Developments in azo disperse dyes derived from heterocyclic diazo components. Dyes Pigm 1999, 42:3-28.

5. Chen C, Wang I: Synthesis of some pyridone azo dyes from 1-substitued 2-hydroxy-6-pyridone derivatives and their colour assessment. Dyes Pigm 1991, 15:69-82.

6. He J, Bian S, Li L, Kumar J, Tripathy S, Samuelson L: Photochemical behavior and formation of surface relief grating on self-assembled polyion/dye composite film. J Phys Chem B 2000, 104:10513-10521.

7. Wang P, Wang I: Photofading of azo pyridone dyes in solution. Part II. Substituent effects on the UV absorption spectra and photostability of 3-(mono- and di-substituted arylazo)-2-hydroxy-4-methyl-5-cyano-6pyridone in N,N-dimethylformamide. Text Res J 1990, 60:519-524.

8. Peng Q, Li M, Gao K, Cheng L: Hydrazone-azo tautomers of pyridone azo dyes Part II. Relationship between structure and $\mathrm{pH}$ values. Dyes Pigm 1991, 15:263-274.

9. Ertan N, Eyduran F: The synthesis of some hetarylazopyridone dyes and solvent effects on their absorption spectra. Dyes Pigm 1995, 27:313-320. 
10. Ertan N, Gurkan P: Synthesis and properties of some azo pyridone dyes and their Cu (II) complexes. Dyes Pigm 1997, 33:137-147.

11. Mijin D, Ušćumlić G, Perišić-Janjić N, Valentić N: Substituent and solvent effects on the UV / vis absorption spectra of 5-(3- and 4-substituted arylazo)-4,6-dimethyl-3-cyano-2-pyridones. Chem Phys Lett 2006, 418:223-229.

12. Mijin D, Baghbanzadeh M, Reidlinger C, Kappe C: The microwave-assisted synthesis of 5-arylazo-4,6-disubstituted-3-cyano-2-pyridone dyes. Dyes Pigm 2010, 85:73-78.

13. Ušćumlić G, Mijin D, Valentić $N$, Vajs $V$, Sušić B: Substituent and solvent effects on the UV/vis absorption spectra of 5-(4-substituted arylazo)-6hydroxy-4-methyl-3-cyano-2-pyridones. Chem Phys Lett 2004, 397:148-153.

14. Roch J, Müller E, Narr B, Nickl J, Haarmann W: 3-Amino-4-phenyl-6-piperidino$1 H$-pyrazolo[3,4-b]-pyridines and salts thereof. U.S. Patent 4; 1981. 260,621 A1, 1981.

15. Peng Q, Li M, Gao K, Cheng L: Hydrazone-azo tautomerism of pyridone azo dyes Part I. NMR spectra of tautomers. Dyes Pigm 1990, 14:89-99.

16. Peng Q, Li M, Gao K, Cheng L: Hydrazone-azo tautomerism of pyridone azo dyes. Part III. Effect of dye structure and solvent on the dissociation of pyridone azo dyes. Dyes Pigm 1992, 18:271-286.

17. Karci F, Karci F: Synthesis and absorption spectra of some novel heterocyclic disazo dyes derived from pyridone and pyrazolone derivatives. Dyes Pigm 2008, 76:147-157.

18. Lucka A, Machacek V: ${ }^{13} \mathrm{C}$ - and ${ }^{15} \mathrm{~N}$-NMR studies of the azo-hydrazone tautomerism of some azo dyes. Dyes Pigm 1986, 7:171-185.

19. Cee A, Horakova B, Lučka A: Structural analysis of substituted 3-arylazo-2hydroxy-6-pyridones. Dyes Pigm 1988, 9:357-369.

20. Kamlet M, Abbound J, Taft R: An examination of linear solvation energy relationships. In Progress in Physical Organic Chemistry, Volume 13. Edited by Taft R. New York: Wiley; 1981:485-630.

21. Kamlet M, Abbound J, Abraham M, Taft R: Linear solvation energy relationships. 23. A comprehensive collection of the solvatochromic parameters, $\pi^{*}, a$, and $\beta$, and some methods for simplifying the generalized solvatochromic equation. J Org Chem 1983, 48:2877-2887.

22. Hammett $L$ : The effect of structure upon the reactions of organic compounds Benzene derivatives. J Am Chem Soc 1937, 59:96-103.

23. Brown $\mathrm{H}$, Okamoto Y: Electrophilic substituent constants. J Am Chem Soc 1958, 80:4979-4987.

24. Becke A: Density-functional exchange-energy approximation with correct asymptotic behavior. Phys Rev [Sect] A 1988, 38:3098-3100.

25. Lee C, Yang W, Parr R: Development of the Colle-Salvetti correlationenergy formula into a functional of the electron density. Phys Rev [Sect] $B$ 1988, 37:785-789.

26. Frisch MJ, Trucks GW, Schlegel HB, Scuseria GE, Robb MA, Cheeseman JR, Montgomery JA Jr, Vreven T, Kudin KN, Burant JC, Millam JM, lyengar SS, Tomasi J, Barone V, Mennucci B, Cossi M, Scalmani G, Rega N, Petersson GA, Nakatsuji H, Hada M, Ehara M, Toyota K, Fukuda R, Hasegawa J, Ishida M, Nakajima T, Honda Y, Kitao O, Nakai H, et al: Gaussian 03, Revision C.02. Wallingford CT: Gaussian Inc; 2004.

doi:10.1186/1752-153X-6-71

Cite this article as: Alimmari et al:: Synthesis, structure and

solvatochromic properties of some novel 5-arylazo-6-hydroxy-4-phenyl3-cyano-2-pyridone dyes. Chemistry Central Journal 2012 6:71.

\section{Publish with ChemistryCentral and every scientist can read your work free of charge \\ "Open access provides opportunities to our colleagues in other parts of the globe, by allowing anyone to view the content free of charge." \\ W. Jeffery Hurst, The Hershey Company. \\ - available free of charge to the entire scientific community \\ - peer reviewed and published immediately upon acceptance \\ - cited in PubMed and archived on PubMed Central \\ - yours - you keep the copyright \\ Submit your manuscript here: \\ http://www.chemistrycentral.com/manuscript/<smiles>c1ccccc1</smiles> \\ Chemistry Central}

